\title{
RELEVANSI PATEN DENGAN KEGIATAN AKADEMIS DAN SEBAGAI DUKUNGAN PENELITIAN PADA PERGURUAN TINGGI
}

\author{
Febri Yandi \\ 155100030,785567838 \\ Fakultas Komputer \\ febriyandi.student@umitra.ac.id
}

\begin{abstract}
Perguruan Tinggi (PT) adalah sebuah tempat terjadinya transfer ilmu pengetahuan dan pertukaran ide yang dinamis di antara para pihak yang terlibat di dalamnya. Transfer ilmu pengetahuan dan pertukaran ide tersebut terjadi melalui berbagai kegiatan tri dharma PT, yaitupengajaran, penelitian, dan pengabdian masyarakat.

Dosen dan mahasiswa di Perguruan Tinggi baik pada disiplin ilmu sosial maupun eksakta mempunyai potensi untuk mendapatkan paten penelitian. Pemilik paten akan mempunyai hak dari eksploitasi komersial selama 20 tahun atau 10 tahun. Beberapa masalah yang harus dihadapi oleh perguruan tinggi dalam paten penelitian adalah status hukum dosen dan mahasiswa sebaga pemegang hak paten, dan aturan-aturan yang harus diambil untuk meningkatkan jumlah paten dalam negeri.

Institusi Pendidikan dalam bidang sains dan teknik potensial untuk menghasilkan paten serta memahami diskripsi paten yang terdapat pada Berita Paten/Informasi Paten. Karena kemampuan ini, maka Institusi Pendidikan dengan bidang kajian di atas diharapkan dapat mengambil peran penting dalam meningkatkan jumlah paten domestik serta dapat melaksanakan serta mengembangkan invensi yang sudah tidak lagi dilindungi oleh paten karena sudah menjadi public domain.
\end{abstract}

Kata Kunci : Paten, Perguruan Tinggi, Relevan Support Researh. 
A. INTRODUCTION

Perguruan Tinggi (PT) adalah sebuah tempat terjadinya transfer ilmu pengetahuan dan pertukaran ide yang dinamis di antara para pihak yang terlibat di dalamnya. Transfer ilmu pengetahuan dan pertukaran ide tersebut terjadi melalui berbagai kegiatan tri dharma PT, yaitupengajaran,

penelitian, dan pengabdian masyarakat. Semua hasil kegiatan pengajaran, penelitian, dan pengabdian masyarakat tersebut merupakan objek perlindungan berbagai hak kekayaan intelektual (HKI), seperti hak cipta, paten, desain industri, merek, desain tata letak sirkuit terpadu (DTLST), perlindungan varietas tanaman (PVT), dan rahasia dagang (RD) yang dapat menjadi milik sebuah PT tanpa bermaksud mengecilkan arti cabangcabang HKI lainnya. Tulisan ini akan fokus menguraikan paten dan relevansinya dengan kegiatan akademis di PT.

Perguruan Tinggi terutama yang kajian bidang ilmunya sains dan teknik potensial untuk menghasilkan penelitian yang bersifat aplikatif, yakni berupa cara kerja tertentu baik itu produk maupun proses. Diharapkan hasil- hasil penelitian tersebut merupakan hal yang baru, yakni belum pernah ada sebelumnya ataupun penyempurnaan/perbaikan dari teknologi yang sudah ada. Kegiatan menghasilkan sesuatu yang baru tentu bukan hal yang mudah. Diperlukan latar belakang ilmu yang baik serta kerja keras hingga menghasilkan teknologi baru. Untuk itu, pantaslah bila kepada peneliti diberi penghargaan atau perlindungan hukum. Apalagi, bila teknologi tersebut merupakan hal yang baru dan memiliki nilai ekonomi yang baik.

Dalam hukum, dikenal pranata hukum yang disebut Paten. Paten merupakan perlindungan hukum yang diberikan kepada pemegang hak atas suatu teknologi baru.

\section{Paten dan Invensi}

Paten merupakan perlindungan hukum yang diberikan atas invensi baru. Yakni cara kerja baru atau perbaikan dari cara kerja yang sudah ada baik berupa produk maupun proses. Cara kerja dari produk dapat berupa: mesin, manufaktur, ataupun komposisi material (banyak dalam bidang kimia). Sementara yang dimaksud dengan proses adalah cara untuk mengerjakan sesuatu.

Jenis perlindungan hukum pada paten bersifat eksklusif, artinya tidak ada orang lain yang dapat melakukan eksploitasi komersial atas paten tersebut, kecuali dengan ijin pemilik 
paten. Banyak negara di dunia mengenal dan mengakui pranata hukum paten. Di Indonesia peraturan yang memberikan perlindungan atas invensi baru adalah Undang Undang Nomor 14 tahun 2001 tentang Paten.

Dalam pasal 1 UU Paten, Paten adalah "hak eksklusif yang diberikan Negara kepada Inventor atas hasil Invensinya di bidang teknologi, yang untuk selama waktu tertentu melaksanakan sendiri Invensinya tersebut atau memberikan persetujuannya kepada pihak lain untuk melaksanakannya. Selanjutnya pada pasal 2 UU yang sama disebutkan bahwa Paten diberikan untuk Invensi baru dan mengandung langkah inventif serta dapat diterapkan dalam industri”.

Dari kalimat di atas dapat dipahami bahwa objek paten, adalah invensi dalam bidang teknologi dan dapat diterapkan secara industri. Atas obyek ini diberikan hak yang bersifat eksklusif, yang berarti hak tersebut khusus diberikan kepada pemegang hak dan mengenyampingkan orang lain untuk mengeksploitasi obyek tanpa ijin pemegang haknya.

Kata invensi berasal dari bahasa Inggris invention yang berarti hasil dari serangkaian kegiatan sehingga tercipta sesuatu yang baru yang tadinya belum ada. Invensi harus dibedakan dari discovery yang berarti mendapatkan sesuatu yang telah ada /tersedia di alam. Sekalipun demikian dalam praktek, beberapa negara maju terutama Amerika Serikat dan Jepang berusaha mendapatkan paten untuk banyak hal termasuk yang kontroversial apakah merupakan discovery atau invention. Pada tahun 2002, Shiseido, sebuah perusahaan kosmetik Jepang

berusaha mematenkan beberapa bahan dasar yang secara tradisional telah digunakan Indonesia sebagai alat kecantikan seperti cabe merah dan brotowali.

\section{B. CONTENT}

Paten adalah hak eksklusif yang diberikan oleh negara kepada penemu atas hasil invensinya di bidang teknologi. Karena paten hanya terbatas diberikan kepada invensi dalam bidang teknologi, beberapa PT yang hanya memiliki fakultas atau jurusan ilmu-ilmu sosial tentulah tidak dapat menghasilkan objek perlindungan hak paten. Paten menjadi HKI yang paling relevan bagi PT yang memang khusus menawarkan program pendidikan terkait teknologi. Sebagai contoh, Institut Teknologi Bandung dan Institut Pertanian Bogor adalah dua PT terdepan di Indonesia 
yang banyak menghasilkan invensi yang dilindungi paten.

Penelitian yang dilakukan oleh PT untuk menghasilkan paten tidak harus selalu melibatkan teknologi tingkat tinggi yang rumit. Hal ini disebabkan paten dapat juga diberikan untuk invensi dalam bidang teknologi yang sederhana. Paten sejenis ini dikenal sebagai paten sederhana(petty

patent atau utility model).

Terdapat beberapa perbedaan antara paten dan paten sederhana. Perbedaan pertama adalah jenis invensi yang dilindungi. Paten memberikan perlindungan untuk invensi dalam bidang teknologi, baik yang bersifat kasat mata (tangible), seperti produk, maupun tidak kasat mata (intangible), seperti proses atau metode. Adapun paten sederhana hanya dapat diberikan untuk invensi dalam bidang teknologi yang kasat mata (tangible), sehingga invensi tersebut harus selalu berbentuk produk. Baik paten maupun paten sederhana harus memenuhi tiga syarat, yaitu baru (novelty), mengandung langkah inventif,dan dapat diproduksi secara massal. Namun, paten sederhana menekankan invensi dalam bidang teknologi baru yang memiliki kegunaan praktis, sehingga persyaratan mengandung langkah inventif lebih mudah dipenuhi bila dibandingkan dengan paten.

Selain itu, karena lebih mudah memenuhi syarat mengandung langkah inventif ini, proses permohonan paten sederhana lebih singkat daripada paten. Menurut UU Paten No. 14/ 2001, paten sederhana dapat dikabulkan dalam waktu 24 bulan sejak tanggal penerimaan aplikasi, sedangkan untuk paten 36 bulan. Demikian pula jangka waktu perlindungan paten sederhana lebih singkat dibandingkan paten. Jangka waktu perlindungan paten sederhana 10 tahun, sedangkan paten 20 tahun. Meskipun demikian, jangka waktu perlindungan keduanya tidak dapat diperpanjang setelah waktu tersebut di atas berakhir. Dari segi biaya, permohonan dan pemeliharaan untuk paten sederhana lebih murah dibandingkan dengan paten. Dalam Peraturan Pemerintah RI No. 38/ 2009 tentang Penerimaan Negara Bukan Pajak yang Berlaku pada Kementerian Hukum dan Hak Asasi Manusia ditetapkan biaya permohonanan paten adalah Rp575.000,00 dan paten sederhana $\mathrm{Rp}$ 125.000,00. Biaya pemeliharaan paten ditetapkan paling murah Rp700.000,00 per tahun dan paten sederhana paling murah Rp550.000,00 per tahun. 
PT di Indonesia dengan segala keterbatasan sumber daya penelitiannya sangat cocok untuk menghasilkan invensiinvensi yang dapat diberikan paten sederhana. Bahkan, tidak hanya dosen atau peneliti karyawan PT tersebut yang dapat menghasilkan invensi yang dilindungi paten sederhana. Kegiatan riset yang dilakukan oleh mahasiswa dapat pula didorong untuk menghasilkan paten sederhana.

Untuk kepemilikan paten, Pasal 12 Ayat (1) UU Paten No. 14/ 2001 mengatur bahwa paten yang dihasilkan oleh pihak dalam suatu hubungan kerja menjadi milik dari pihak yang memberikan pekerjaan tersebut, kecuali bila diperjanjikan lain. Dalam konteks invensi yang dihasilkan oleh dosen atau peneliti di lingkungan PT, pemilik paten adalah PT yang mempekerjakan dosen atau peneliti tersebut. Ayat selanjutnya mengatur bahwa paten atas invensi yang dihasilkan oleh karyawan yang menggunakan data dan/ atau sarana yang tersedia dalam pekerjaannya walaupun dalam perjanjian kerjanya karyawan tersebut tidak diharuskan menghasilkan invensi, tetap menjadi milik pihak yang mempekerjakannya. Ayat kedua ini berlaku dalam keadaan ada karyawan nonakademis yang mempergunakan data dan/ atau sarana yang tersedia di lingkungan PT untuk menghasilkan suatu invensi yang memperoleh paten. Namun, walaupun kepemilikian paten ada pada PT, Pasal 12 Ayat (3) mengatur bahwa inventor tetap mendapatkan imbalan layak atas manfaat ekonomi dari paten atas invensinya.

Untuk paten atas invensi yang dihasilkan oleh mahasiswa, kedua ayat ini tidak dapat diberlakukan karena mahasiswa tidak terikat hubungan kerja dengan PT tempat mereka belajar. Karena UU Paten No. 14/ 2001 tidak mengatur mengenai kepemilikan paten atas invensi yang ditemukan oleh mahasiswa, pihak PT dapat mengatur sendiri mengenai hal ini. Biasanya, PT di luar negeri membuat perjanjian tertulis dengan mahasiswa pada awal riset mereka yang mengatur kepemilikan paten atas invensi yang dihasilkan riset tersebut. Siapa pemilik paten tersebut tergantung dari kontribusi yang diberikan oleh para pihak dalam riset tersebut. Bila data dan/ atau sarana penelitian, seperti laboratorium, merupakan milik PT, biasanya PT akan mengklaim kepemilikan paten yang dihasilkan dari riset tersebut. 
Dapat pula terjadi, kepemilikan paten jatuh pada pihak ketiga bila riset tersebut dibiayai keseluruhan atau sebagian oleh pihak ketiga tersebut.

\section{Paten yang dihasilkan Institusi Pendidikan:}

Bila suatu paten dari suatu penelitian dihasilkan oleh institusi pendidikan, maka yang terlibat dalam perolehan invensi, selain peran institusi itu sendiri, juga peran dari dosen dan para mahasiswa yang terlibat. Besarnya peran dosen/mahasiswa dalam menghasilkan invensi di institusi pendidikan menimbulkan pertanyaan bagaimana hak dari para pihak yang terlibat tersebut ? Seperti telah ditulis sebelumnya, karena kedudukan hukum serta sifat pekerjaan dosen dan mahasiswa pada institusi pendidikan berbeda dengan kedudukan majikan (employer) dan buruh (employee) maka bisa terjadi permasalahan bahkan sengketa apakah institusi lebih berhak untuk mendapatkan paten atas invensi yang dihasilkan karena kedudukannya sebagai majikan, atau dosen/mahasiswa yang lebih berhak atas paten dari invensi yang dihasilkan karena kedudukan mereka selaku inventor.

Beberapa hal yang patut dipertimbangkan dalam menentukan pemilik invensi sehubungan kedudukan khusus Dosen /Mahasiswa:

Dosen:

- Dosen adalah profesional yang berhak meningkatkan kemampuannya secara mandiri, sehingga apa yang dihasilkan bisa dikategorikan sebagai milik pribadi, dan bukan milik institusi.

- Tidak jelas apakah invensi yang dihasilkan termasuk dalam isi kontrak kerjanya dengan institusi.

- Sulit menentukan apakah invensi dihasilkan dalam jam kerja dosen tersebut.

- Bagaimana bila invensi dihasilkan merupakan pengembangan dari invensi milik institusi yang telah ada sebelumnya?

Mahasiswa:

- Jelas bahwa Mahasiswa bukan employee, akan tetapi:

- Apakah fasilitas institusi yang digunakan dalam upaya menghasilkan invensi termasuk fasilitas mahasiswa sesuai haknya karena telah membayar biaya pendidikan?

- Akan lebih sulit menentukan status invensi bila mahasiswa tersebut memperoleh beasiswa hanya sebagian dari institusi . 
Untuk mengurangi bahkan menghilangkan sengketa kepemilikan paten yang mungkin terjadi, sebaiknya institusi dan dosen/mahasiswa membuat kesepakatan untuk menentukan hak dan kewajiban masing-masing dalam hal adanya invensi yangdihasilkan di institusi pendidikan.

Bilamana kendala pendaftaran dalam hal dana, sementara tidak ada kejelasan siapakah yang berhak atas paten, inventor dapat melakukan beberapa hal, seperti:

- Menyerahkan hak kepemilikan invensi kepada institusi

- Meminta agar institusi mendaftarkan invensinya untuk mendapatkan Paten.

- Mencari "grant" dari pemerintah untuk biaya pendaftaran Paten.

\section{Inventor dan bantuan dari} profesional yang kompeten:

Meskipun paten memberikan hak yang besar kepada pemegang haknya, paten bukanlah satu-satunya muara pada setiap invensi yang dihasilkan. Haruslah disadari bahwa paten diberikan untuk memberi perlindungan ekonomi kepada pemegang hak. Bila tidak ada kepentingan ekonomi yang perlu dijaga, karena invensi yang dihasilkan tidak memiliki nilai ekonomi yang baik pendaftaran paten tidak ada gunanya. Bahkan pendaftaran paten hanya memberikan beban ekonomi bagi pemohon karena harus membayar biaya pendaftaran dan pemeliharaan paten.

Bila atas suatu hasil riset ingin dipatenkan, untuk menjamin perlindungan hukum, aspek teknis dan aspek ekonomis dari invensi tersebut, ada baiknya inventor menghubungi profesional yang kompeten sebelum pendaftarkan dilakukan.

Pada dasarnya dibutuhkan 3 profesional yang kompeten dalam menentukan apakah hasil riset itu sebaiknya didaftarkan untuk memperoleh paten, atau tidak. Ketiga jenis profesional dan jenis bantuannya adalah sebagai berikut :

1. Profesional bidang ekonomi, untuk menghitung keuntungan ekonomi yang akan diperoleh bila hasil riset dipatenkan.

2. Profesional teknis, yaitu ahli bidang yang berkaitan dengan invensi, untuk membantu menjabarkan diskripsi invensi dan claim yang diinginkan sehingga aplikasi paten memenuhi syarat yang ditentukan oleh Ditjen HKKI atau Kantor 
Paten luar negeri, bila paten mau didaftarkan di luar negeri.

3. Profesional dalam bidang hukum, serta profesional bidang hukum untuk penanganan masalah hak dan kewajiban pemegang paten .

Simultan dengan advis dari ketiga profesional di atas, beberapa hal yang sebaiknya dipikirkan oleh inventor, adalah:

1. Apakah invensinya memiliki prospek ekonomi yang baik, dan bagaimana meningkatkan nilai ekonomi dari invensi tersebut?

2. Adakah perlindungan hukum tertentu untuk invensi tersebut?

3. Bila akan dipatenkan, halhal apa yang harus dilakukan, dan perlindungan hukum apa yang diberikan atas invensi yang mendapatkan paten?

4. Bila tidak akan dipatenkan, hal-hal apa saja yang harus diperhatikan /harus dilakukan oleh inventor?

5. Pendaftaran paten mewajibkan inventor untuk membuat aplikasi paten. Bagaimana cara pembuatan aplikasi paten yang baik?
Paten hanya akan diberikan bila invensi bersifat baru.
6. Bagi Dosen dan Mahasiswa: sejauh manakah hak Dosen/Mahasiswa terhadap invensi yang mereka hasilkan?

Agar kedudukan hukum yang bersangkutan dalam kaitannya dengan invensi yang dihasilkan jelas, sebaiknya dibuat aturan dan perjanjian yang jelas.

\section{CONCLUSION}

Institusi Pendidikan dalam bidang sains dan teknik potensial untuk menghasilkan paten serta memahami diskripsi paten yang terdapat pada Berita Paten/Informasi Paten. Karena kemampuan ini, maka Institusi Pendidikan dengan bidang kajian di atas diharapkan dapat mengambil peran penting dalam meningkatkan jumlah paten domestik serta dapat melaksanakan serta mengembangkan invensi yang sudah tidak lagi dilindungi oleh paten karena sudah menjadi public domain.

Hingga saat ini, belum banyak paten yang dihasilkan oleh putra-putri Indonesia. Dari tahun 1991 sampai dengan 2002, jumlah paten domestik hanya 258 buah, sementara paten luar negeri berjumlah 9274. Prosentasi ini masih terlalu kecil dan harus 
ditingkatkan, karena peningkatan paten domestik juga menjadi indikator kreativitas dan kemajuan bangsa $^{5}$. Pemerintah amat menginginkan prosentasi Paten Domestik menjadi jauh lebih baik dari keadaan sekarang.

Kebijakan pemerintah untuk peningkatan Paten domestik yang berkaitan dengan dunia pendidikan, yaitu dengan pemberian nilai kum yang tinggi atas penelitian yang mendapatkan paten. Selain itu Menteri Negara Riset dan Teknologi juga memiliki beberapa kebijakan yang dapat dimanfaatkan oleh dunia pendidikan khususnya pendidikan teknologi misalnya: program OLEH Paten yang memberi bantuan bagi peneliti yang mau mendaftarkan patennya, program SENTRA HKI, Program STANLAB, Program Asuransi Teknologi, dan Sentra PROMPTEK

\section{DISCUSSION}

1. Hasil riset yang dapat dimintakan paten, adalah hasil riset yang bersifat inventif, yakni yang menghasilkan cara kerja yang bersifat: baru, hasil yang tidak terbayang sebelumnya oleh ahli di bidang yang sama, memiliki kegunaan sesuai aplikasi paten, dan dapat diterapkan dalam industri.
2. Paten merupakan perlindungan hukum yang diberikan negara kepada inventor atau yang mendaftarkan invensi itu untuk melakukan eksploitasi komersial atas invensi yang dihasilkan selama jangka waktu 20 atau 10 tahun. Masyarakat tidak boleh membuat, menjual, mengimport produk/proses yang dipatenkan tanpa ijin pemilik hak. Tetapi setelah masa perlindungan hukum berakhir, masyarakat dapat secara bebas menggunakan informasi paten dan mengeksploitasinya tanpa ijin (eks) pemilik paten.

3. Paten tidak diperoleh secara otomatis, harus dilakukan pendaftaran ke Direktorat Jendral HKI yang akan memeriksa kelayakan invensi tersebut. Sebelum melakukan pendaftaran harus dikaji lebih dahulu potensi ekonomi dari invensi yang mau dipatenkan, untuk itu diperlukan bantuan ahli yang kompeten yang akan melihat potensi ekonomi, cara pembuatan aplikasi paten, serta aspek perlindungan hukum pendaftar paten.

4. Perguruan tinggi berbasis sains dan teknik diharapkan dapat menghasilkan penelitian yang berpotensi paten. Dosen maupun mahasiswa pada institusi seperti ini berpotensi menghasilkan invensi. Hubungan hukum lembaga pendidikan dengan dosen/mahasiswa dalam beberapa hal tidak sama dengan hubungan hukum antara majikan dan buruh. Dalam UU Paten hanya diatur 
kedudukan majikan dalam hal buruhnya menghasilkan invensi berpotensi paten. Maka kejelasan kedudukan hukum dosen/mahasiswa harus dipertegas dengan perjanjian khusus.

5. Pemerintah menghendaki adanya peningkatan jumlah paten domestik, karenanya amat diharapkan peran Perguruan Tinggi untuk menghasilkan invensi dan melakukan pendaftaran paten. Kementerian Ristek memiliki beberapa program untuk membantu Perguruan Tinggi agar dapat menyumbangkan paten bagi negara, di samping adanya insentif berupa pemberian nilai kum yang tinggi kepada dosen yang menghasilkan paten.

6. Institusi Pendidikan diharapkan berperan aktif serta jeli menggunakan informasi paten yang sudah menjadi public domain untuk kemajuan pendidikan dan pengembangan teknologi di Indonesia. 


\section{E. REFERENCE}

[1] O. M. Febriani and A. S. Putra, "Sistem Informasi Monitoring Inventori Barang Pada Balai Riset Standardisasi Industri Bandar Lampung," J. Inform., vol. 13, no. 1, pp. 90-98, 2014.

[2] A. S. Putra, "Paperplain: Execution Fundamental Create Application With Borland Delphi 7.0 University Of Mitra Indonesia," 2018.

[3] A. S. Putra, "2018 Artikel Struktur Data, Audit Dan Jaringan Komputer," 2018.

[4] A. S. Putra, "ALIAS MANAGER USED IN DATABASE DESKTOP STUDI CASE DB DEMOS."

A. S. Putra, "COMPREHENSIVE SET OF PROFESSIONAL FOR DISTRIBUTE COMPUTING."

[6] A. S. Putra, "DATA ORIENTED RECOGNITION IN BORLAND DELPHI 7.0."

[7] A. S. Putra, "EMBARCADERO DELPHI XE 2 IN GPUPOWERED FIREMONKEY APPLICATION."

[8] A. S. Putra, "HAK ATAS KEKAYAAN INTELEKTUAL DALAM DUNIA TEKNOLOGY BERBASIS REVOLUSI INDUSTRI 4.0."

[9] A. S. Putra, "IMPLEMENTASI PERATURAN

PERUNDANGAN UU. NO 31 TAHUN $2000 \quad$ TENTANG DESAIN INDUSTRI BERBASIS INFORMATION TECHNOLOGY."
[10] A. S. Putra, "IMPLEMENTATION OF PARADOX DBASE."

[11] A. A. S. Putra, "IMPLEMENTATION OF TRADE SECRET CASE STUDY SAMSUNG MOBILE PHONE."

[12] A. S. Putra, "IMPLEMENTATION

PATENT FOR APPLICATION WEB BASED CASE STUDI WWW. PUBLIKLAMPUNG. COM."

[13] A "IMPLEMENTATION SYSTEM FIRST TO INVENT IN DIGITALLY INDUSTRY."

[14] A. S. Putra, "MANUAL REPORT \& INTEGRATED DEVELOPMENT

ENVIRONMENT BORLAND DELPHI 7.0."

[15] A. S. Putra, "PATENT AS RELEVAN SUPPORT RESEARCH."

[16] A. S. Putra, "PATENT FOR RESEARCH STUDY CASE OF APPLE. Inc."

[17] A. S. Putra, "PATENT PROTECTION FOR APPLICATION INVENT."

[18] A. S. Putra, "QUICK REPORT IN PROGRAMMING." PROPERTY

[19] A. S. Putra, "REVIEW CIRCUIT LAYOUT COMPONENT

REQUIREMENT ON ASUS NOTEBOOK."

[20] A. S. Putra, "REVIEW TRADEMARK PATENT FOR INDUSTRIAL TECHNOLOGY BASED 4.0."

[21] A. S. Putra, "TOOLBAR 
COMPONENT PALLETTE IN OBJECT ORIENTED

PROGRAMMING."

[22] A. S. Putra, "WORKING DIRECTORY SET FOR PARADOX 7."

[23] A. S. Putra, "ZQUERY CONNECTION

IMPLEMENTED

PROGRAMMING

STUDI

CASE PT. BANK BCA Tbk."

[24] A. S. Putra, D. R. Aryanti, and I. Hartati, "Metode SAW (Simple Additive Weighting) sebagai Sistem Pendukung Keputusan Guru Berprestasi (Studi Kasus: SMK Global Surya)," in Prosiding Seminar Nasional Darmajaya, 2018, vol. 1, no. 1, pp. 85-97.

[25] A. S. Putra and O. M. Febriani, "Knowledge Management Online Application in PDAM Lampung Province," in Prosiding International conference on Information Technology and Business (ICITB), 2018, pp. 181-187.

[26] A. S. Putra, O. M. Febriani, and B. Bachry, "Implementasi Genetic Fuzzy System Untuk Mengidentifikasi Hasil Curian Kendaraan Bermotor Di Polda Lampung," SIMADA (Jurnal Sist. Inf. dan Manaj. Basis Data), vol. 1, no. 1, pp. 21-30, 2018.

[27] A. S. Putra, H. Sukri, and K. Zuhri, "Sistem Monitoring Realtime Jaringan Irigasi Desa (JIDES) Dengan Konsep Jaringan Sensor Nirkabel," IJEIS (Indonesian J. Electron. Instrum. Syst., vol. 8, no. 2, pp. 221-232.
[28] D. P. Sari, O. M. Febriani, and A. S. Putra, "Perancangan Sistem Informasi SDM Berprestasi pada SD Global Surya," in Prosiding Seminar Nasional Darmajaya, 2018, vol. 1, no. 1, pp. 289-294. 